NBER WORKING PAPER SERIES

\author{
ARE AFFIRMATIVE ACTION HIRES \\ LESS QUALIFIED? EVIDENCE FROM \\ EMPLOYER-EMPLOYEE DATA ON \\ NEW HIRES
}

\author{
Harry Holzer \\ David Neumark
}

Working Paper 5603

\author{
NATIONAL BUREAU OF ECONOMIC RESEARCH \\ 1050 Massachusetts Avenue \\ Cambridge, MA 02138 \\ June 1996
}

We are grateful to Jess Reaser for outstanding research assistance, to the Rockefeller Foundation for financial support, and to Jeff Biddle, Robert Lalonde, and seminar participants at Michigan State University, Ohio State University, the Upjohn Institute, and the NBER for helpful comments. This paper is part of NBER's research program in Labor Studies. Any opinions expressed are those of the authors and not those of the National Bureau of Economic Research.

(C) 1996 by Harry Holzer and David Neumark. All rights reserved. Short sections of text, not to exceed two paragraphs, may be quoted without explicit permission provided that full credit, including $(\mathbb{C}$ notice, is given to the source. 


\title{
ARE AFFIRMATIVE ACTION HIRES \\ LESS QUALIFIED? EVIDENCE FROM \\ EMPLOYER-EMPLOYEE DATA ON \\ NEW HIRES
}

\begin{abstract}
In this paper we use micro-level data on employers and employees to investigate whether Affirmative Action procedures lead firms to hire minority or female employees who are less qualified than workers who might otherwise be hired. Our measures of qualifications include the educational attainment of the workers hired (both absolutely and relative to job requirements), skill requirements of the job into which they are hired, and a variety of outcome measures that are presumably related to worker performance on the job. The analysis is based on a representative sample of over 3,200 employers in four major metropolitan areas in the U.S. Our results show some evidence of lower educational qualifications among blacks and Hispanics hired under Affirmative Action, but not among white women. Further, our results show little evidence of substantially weaker job performance among most groups of minority and female Affirmative Action hires.
\end{abstract}

Harry Holzer

Department of Economics

Michigan State University

East Lansing, MI 48824
David Neumark

Department of Economics

Michigan State University

East Lansing, MI 48824

and NBER 


\section{Introduction}

Affirmative Action policies have always been controversial, largely because of the allegation that they cause employers (and universities) to prefer less-qualified minorities or females over morequalified white males. Survey evidence suggests that, even among whites, there is widespread public support for outlawing employment discrimination and also for policies that compensate the past victims of discrimination through targeted education, job training, and recruitment efforts. At the same time, policies that give "preference" in employment or university admissions to less-qualified members of these groups are strongly opposed (e.g., Lipset and Schneider, 1978; Bobo and Smith, 1994). ${ }^{1}$

Similarly, many critics of Affirmative Action policies support strong enforcement of EEO laws and even compensatory recruitment and training, but argue that the alleged preferences for lessqualified minorities and females in most current Affirmative Action practices create labor market inefficiencies and/or inequities. ${ }^{2}$ In contrast, proponents of Affirmative Action policies frequently argue that labor market discrimination continues to be prevalent, despite EEO laws. ${ }^{3}$ They also argue that gaps in the relative qualifications of different groups (when measured by educational attainment,

\footnotetext{
${ }^{1}$ In these data, much hinges on the wording of questions describing Affirmative Action; references to "quotas" or "reverse discrimination" generally elicit the most negative responses. There is also some evidence of more tolerance for compensatory policies in education than in employment, though quotas or other forms of preferences in university admissions are still widely opposed. For a view that distinguishes Affirmative Action in universities from that in employment see Carter (1991).

${ }^{2}$ Critics of current Affirmative Action policies that stress both inefficiencies and inequities (from violating principles of rewards based on individual merit) include Glazer (1975), Epstein (1992) and Sowell (1990). Coate and Loury (1993) argue that Affirmative Action can reduce the incentives of "preferred" groups to invest in human capital formation, while Carter (1991) also emphasizes the stigma borne by qualified minorities because of these policies.

${ }^{3}$ Evidence of discrimination against minorities or females, even when controlling for observable credentials, can be found in several recent "audit" studies of employers (e.g., Fix and Struyk, 1994; Neumark, forthcoming), in which matched pairs of applicants with comparable credentials but differing race/gender are sent out to apply for specific jobs.
} 
experience, etc.) likely reflect past or current discrimination, ${ }^{4}$ and that such qualifications are weak predictors of actual performance on the job (which itself may be difficult to measure, especially in the short term). ${ }^{5}$ In this view, the efficiency costs of preferential policies are considered very small or even negative (since these policies might actually lead to the hiring of more productive minorities and females).

The current debate on Affirmative Action thus turns heavily on the existence and empirical magnitudes of shortfalls in qualifications and job performance of women and minorities hired under Affirmative Action. Yet, despite the intensity of the viewpoints held, the evidence to date on this issue remains quite thin. To the best of our knowledge, the only systematic empirical study of the effects of Affirmative Action on productivity in employment is that of Jonathan Leonard (1984). ${ }^{6}$ He estimates production functions using state-by-two-digit industry data in manufacturing, in which the fractions of employment accounted for by minorities/females and by federal contractors (who are typically required to have Affirmative Action plans) appear as independent variables. But the usefulness of this approach is limited by the highly aggregated nature of the data and its focus only on manufacturing. ${ }^{7}$ Also, Badgett (1995) provides more qualitative evidence on the effects of Affirmative Action on the qualifications of minority hires from a case study of a large manufacturing

\footnotetext{
${ }^{4}$ For instance, Bergmann (1989) stresses that occupation-specific experience requirements effectively discriminate against women who have been barred from gaining such experience because of occupational segregation by gender.

${ }^{5}$ The difficulty of predicting or observing individual-level productivity has been stressed in the "statistical discrimination" literature (e.g., Cain, 1986), and more recently by Oettinger (1996) and Altonji and Pierret (1996). The question of whether required qualifications accurately predict job performance, and whether any resulting "disparate impacts" across demographic groups can be considered discrimination, has been addressed in a variety of court cases (e.g., Griggs v. Duke Power in 1971 and Ward Cove v. Atonio in 1989) and in the Civil Rights Act of 1991. The debate over the latter, including the allegations of critics that such legislation constituted a "quota bill," indicates the difficulties of distinguishing strong EEO policies from preferential treatment.
}

${ }^{6}$ Most of Leonard's papers deal with the effects of Affirmative Action on relative employment, occupational status, and the like. These are reviewed in various survey papers $(1989,1990)$.

${ }^{7}$ Given the small effects of Affirmative Action on the overall composition of employment that Leonard shows in his other work, it is very unlikely that he would find strong effects on productivity at the two-digit industry level. 
firm, and concludes that - at this company - Affirmative Action did not result in lower-quality hires, based in part on evidence that upper-level management promoted Affirmative Action as a means of finding the best employees. ${ }^{8}$

In this paper, we provide what we believe to be the first micro-level empirical evidence on the relative qualifications of workers hired under Affirmative Action. Using data on new hires collected from employers, we are able to compare the qualifications of women or minorities hired under Affirmative Action to those of white men in comparable jobs, and to those of women or minorities hired in firms that do not use Affirmative Action. Of course, workers' qualifications and performance are difficult to measure. We therefore take a broad-ranging approach, focusing on a wide variety of variables related to both initial qualifications as well as performance on the job.

\section{The Data}

\section{The Sample}

The data are drawn from a survey that was administered to 800 employers in each of four metropolitan areas: Atlanta, Boston, Detroit, and Los Angeles. ${ }^{9}$ The survey was administered between June of 1992 and May of 1994, as the national economy was recovering from the recession of the early 1990 s. $^{10}$

\footnotetext{
${ }^{8}$ Regarding college admissions, Loury and Garman (1995) and Kane (1995) present evidence of gaps in SAT scores between white and black college students, to infer the effects of Affirmative Action on college admissions. The former study suggests that preferential admissions policies lead blacks with low test scores to attend (and frequently drop out from) colleges with higher average test scores. The latter suggests that these results mostly reflect differences in highschool performance and family background rather than preferential admissions for blacks.
}

${ }^{9}$ The survey is part of a broader project known as the Multi-City Study of Urban Inequality, that consists of household surveys and an in-depth, qualitative study of a smaller sample of employers in each of these four metropolitan areas. The project has been financed by the Ford and Russell Sage Foundations (Holzer, 1996a). These data are also used in Holzer (1995 and 1996b).

\footnotetext{
${ }^{10}$ The survey was administered to firms in Detroit between June 1992 and February 1993; it was administered in the other areas between March 1993 and May 1994. The timing was deliberately chosen in order to coordinate with the
} 
The survey was administered over the phone, and averaged roughly 35 minutes in length. The sample of firms was drawn from two sources: 1) a listing of firms and their phone numbers provided by Survey Sampling, Inc. (SSI); and 2) the employers of respondents in the household surveys that were also administered in each of these four metropolitan areas. ${ }^{11}$ The latter were drawn in order to generate a sample of "matched pairs" of individuals and employers. For the firms in the SSI part of the sample, the respondent to the survey is the person who is responsible for hiring non-college workers. For the sample drawn from the household survey, the respondent is the person responsible for hiring into the occupation of the household respondent. ${ }^{12}$

A number of steps were taken to ensure that the data could be used to draw inferences regarding the underlying population. Sample weights were generated to account for any differences in firm characteristics that might be attributable to these different sampling strategies, so that we can pool data from these two sources. Despite the differences between these two sources, both were designed to generate employee-weighted samples of firms. For the SSI sample, this was accomplished by ex ante stratification of the sample based on establishment size, with the distribution of firms chosen to approximate the distribution of employees across size categories in the workforce. ${ }^{13}$ For the household-generated sample, the distribution of firms should approximate the

surveying of households in each area, as part of the Multi-City study described above. Monthly unemployment rates averaged under six percent in Atlanta and Boston during the survey period; in Detroit and Los Angeles they averaged roughly eight percent and under ten percent respectively during the relevant periods. Dummy variables for metropolitan area and year of survey are included in the multivariate analyses that follow to control for these differences in local labor market conditions.

\footnotetext{
${ }^{11}$ The SSI listings are drawn primarily from local phone directories that are supplemented by other sources. For another example of employer data drawn from SSI listings, see Barron, et al. (1994).

${ }^{12}$ Most characteristics of workers and jobs do not differ significantly across the samples of firms generated by the two data sources.

${ }^{13}$ The stratification scheme was: 25 percent in establishments with fewer than 20 employees; 50 percent in establishments with 20-99 employees; and 25 percent in those with 100 or more employees. These distributions were drawn from a weighted sample of firms in the Employment Opportunity Pilot Project (EOPP) of 1980 and 1982.
} 
distribution of employment in the population by construction (at least when sample-weighted). Thus, no additional size-weighting of firms is necessary with this sample. ${ }^{14}$ When focusing on the characteristics of each firm's most recently-filled job, the sample will provide extra weight to firms that do a lot of hiring because of their size (but not because of high turnover). ${ }^{15}$ The sample of new jobs should thus reasonably approximate the available stock of jobs.

The overall response rate for the survey was roughly 67 percent for firms that were successfully screened. ${ }^{16}$ This response rate compares quite favorably with other surveys of employers administered over the phone (e.g., Kling, 1995). In addition, because we have some measured characteristics of firms in the SSI sample that did not respond to the survey (i.e., establishment size, industry, and location), we could check for differences in response rates across these observable categories that might generate sample selection bias. Few significant differences were found in response rates across the categories measured by these variables. ${ }^{17}$

Comparisons of the industries and sizes of firms in our sample were also made with firms in the most recently available published data from County Business Patterns for these metropolitan areas, and the two samples appeared to be quite comparable. ${ }^{18}$ Finally, we compared the distribution

\footnotetext{
${ }^{14}$ Sample weights are applied to the household-generated firms that adjust for: 1) the underrepresentation of jobs requiring college, since the SSI sample focused on non-college jobs; 2 ) the oversampling of low-income and minority residents in the household surveys; and 3) the incompleteness of the Boston and Los Angeles samples of households from which employers were drawn. More information on the construction of these weights is available from the authors.

${ }^{15}$ The lack of extra weighting for high-turnover firms seems appropriate, since a single job that turns over frequently is only available to a single worker at any time. Unfortunately, there was no easy way to put extra weight on firms whose rate of hiring is temporarily high due to their net employment growth.

${ }^{16}$ Successfully screened firms were those where the correct firm and the person responsible for new hiring into the relevant types of positions were contacted, and where the firm had hired someone in the past three years into one of those positions.
}

${ }^{17}$ For more details see Holzer (1996a). Only response rates among firms in construction and in the smallest size category were significantly lower than others, while those in the public sector and the largest establishments were significantly higher. But response rates were within .10 of the mean (.67) in all of these categories.

${ }^{18}$ The published data show that jobs in retail trade, the services, and manufacturing account for $.17-.21, .31-.40$, and 
of occupations among our most recently-filled jobs with that in the 1990 Census of Population for these areas, and with the distributions of occupations and worker characteristics among all employees in our firms, to see whether or not the sample of "marginal" employees (i.e., new hires) differs greatly from the "average." We found only minor evidence of this. ${ }^{19}$

\section{Variables Used in the Study}

The variables used in this study are primarily drawn from survey questions on the last job filled and the worker hired into that job. In particular, respondents were asked whether or not "Affirmative Action or Equal Opportunity Law play any role in your recruiting activities for this position," and also whether or not these factors play any role in terms of who is hired. The measure we use for Affirmative Action in this paper is the latter. ${ }^{20}$

Given the wording of the question, there may some ambiguity over whether we are picking up the effects of Affirmative Action or EEO law more generally. However, the evidence suggests that while EEO law technically refers to Title VII of the Civil Rights Act, companies interpret this question to mean Affirmative Action. All firms with 15 or more employees are bound by Title VII of the Civil Rights Act, and hence, by Equal Employment Opportunity law; ${ }^{21}$ in contrast, a smaller subset of firms have Affirmative Action plans. Because only 45 percent of our firms (on an employee-weighted basis) report any role for Affirmative Action or EEO law in hiring, we assume that respondents were generally indicating whether the firm used an explicit Affirmative Action

13-.24 of total employment in these areas. The distribution of employment across industries in the survey is very comparable to these figures.

\footnotetext{
${ }^{19}$ For instance, the new hires contain fewer white males (.26 vs. .32), more blacks, (.20 vs. .17), and more blue-collar workers (.35 vs. .26) than do all current employees.

${ }^{20}$ Lower qualifications or performance are more likely when Affirmative Action is used in hiring rather than in recruiting. In addition, data on Affirmative Action in hiring are obviously more pertinent to who actually gets hired, which is the focus of the policy debate.
}

${ }^{21}$ Bloch (1994) estimates that under 20 percent of the private sector workforce is not covered by Title VII. 
policy. Even this, however, is ambiguous, since Title VII instructs courts to "order such affirmative action as may be appropriate, which may include ... reinstatement or hiring of employees ..." when employers are found guilty of discrimination.

However, we believe that we are generally measuring Affirmative Action plans as prescribed by Executive Order 11246 or voluntary plans adopted by employers. ${ }^{22}$ Although our self-reported measure is not based directly on federal contractor status, as was Leonard's, the fraction of establishments reporting using Affirmative Action, and their characteristics, are similar in our sample and Leonard's, suggesting that our classification scheme does not differ greatly from his. In particular, roughly 60 percent of the establishments used by Leonard are classified as federal contractors, in a sample drawn from filers of EEO-1 forms (which represents all establishments above 100 employees, all over 50 with federal contracts, and all over 25 in multi-establishment firms). ${ }^{23}$ In our size-weighted sample of establishments, 60 percent report some use of Affirmative Action/EEO in recruiting or hiring. Use of Affirmative Action is highly correlated with establishment size in both samples.

Thus, the classification of firms by Affirmative Action status in our data displays similar patterns to the classification based on federal contractor status in Leonard's data. The correspondence on a firm-by-firm basis is undoubtedly imperfect. It is not obvious, though, that self-reported Affirmative Action status is an inferior measure. Given that there is imperfect compliance with Affirmative Action guidelines for federal contractors (as emphasized, e.g., by Leonard, 1989), and

\footnotetext{
${ }^{22}$ Affirmative Action may be implemented for one of three main reasons. First, it is mandatory for firms with federal contracts with 50 or more employees or a contract worth $\$ 50,000$ or more (Leonard, 1989). Second, it may be implemented by the courts as a remedy for a finding of past discrimination (see the discussion in Epstein, 1991, Ch. 19). Third, Affirmative Action hiring may be used as a deterrent to claims of discrimination under Title VII (see the case study discussed in Badgett, 1995, p. 493), or to increase workplace diversity for other reasons. Voluntary Affirmative Action plans are permitted if they are based on specific plan, correct a previous imbalance, protect the interests of nonAffirmative Action candidates, and will end when specific goals are met (Gold, 1993).
}

${ }^{23}$ Beginning in 1983, only the first two types of establishments had to file (Rodgers and Spriggs, 1996). 
given that non-contractors can have Affirmative Action plans, a measure of Affirmative Action use based on what firms perceive themselves to be doing may in fact be preferable to, or at least as good as, a measure based on federal contractor status. ${ }^{24}$

The other job-specific questions include whether or not a college degree is required for the job; whether or not high school, specific previous experience, vocational training, or references are each required, ${ }^{25}$ whether each of a set of tasks (dealing with customers directly, reading or writing paragraphs, arithmetic, or computer use) is performed daily on the job; and a set of one-digit occupational dummies. The characteristics of the last worker hired include race/ethnicity, sex, age, and educational attainment. Firm-specific characteristics include establishment size, percent of workforce covered by collective bargaining, one-digit industry dummy variables, and dummy variables for location within the central city of the MSA. We also use variables for the race and gender of the respondent to the survey, and the racial composition of the firm's customer pool, to control as much as possible for determinants of racial or gender preferences among survey respondents.

\section{Descriptive Information on Hiring in Firms by Use of Affirmative Action}

\section{Descriptive Statistics}

We begin in Table 1 by providing simple descriptive information on differences between worker-firm matches in which Affirmative Action is used in hiring and those in which it is not. In subsequent tables we turn to the differences between minorities and white females who are hired into

\footnotetext{
${ }^{24}$ Because the survey used in this paper was not designed explicitly to study Affirmative Action, the survey did not elicit information that might further clarify the interpretation of the question.

${ }^{25} \mathrm{We}$ code most of these requirements as dummy variables which take on a value of one if the requirement is "absolutely necessary" or "strongly preferred" at the time of hiring and zero if it is "mildly preferred" or "doesn't matter." In contrast, the college requirement is based on an explicit "yes" or "no" question in the survey.
} 
firms that use Affirmative Action, relative to other groups of workers.

Looking first at demographic characteristics of recent hires, we see that the largest absolute difference between hires based on Affirmative Action and those that are not is between white males and females, where the proportion of recent hires accounted for by these groups is .06 lower and .07 higher, respectively, when Affirmative Action is used in hiring. The proportions of recent hires among the other demographic groups are not very different between Affirmative Action and nonAffirmative Action hiring; the proportions of black females and Hispanic males are actually slightly lower. Of course, these are univariate comparisons, and the influence of Affirmative Action on hiring by demographic group may change once account is taken of firm, job, and other individual characteristics. ${ }^{26}$

The second panel of Table 1 provides information on worker education, while the third panel provides descriptive information on job requirements for the jobs into which the recent hiring occurred. We see that workers hired under Affirmative Action tend to be more educated, and that skill requirements are higher for these jobs for each of the requirements listed in the table. These results suggest that we may have to compare qualifications of women and minorities relative to white males within the subset of firms using Affirmative Action; otherwise, we might incorrectly conclude that Affirmative Action hires are more qualified. This issue receives considerable attention in the empirical analysis.

Consistent with the above results, the fourth panel in Table 1 reveals that a greater proportion of hiring in firms using Affirmative Action is into management/professional and clerical jobs than

\footnotetext{
${ }^{26}$ These results also differ somewhat from those of Leonard (1989) for the 1970's, who finds proportionately bigger effects on black males and females than on white females. But during the 1980's Leonard finds relative employment of black males and females declining at contractor establishments (relative to non-contractors), which is consistent with the findings reported here and in Table 2 . The results are partly consistent with those reported by Rodgers and Spriggs (1996), who find that federal contractor status is associated with a higher percentage of black workers (by 12 percent) and a lower percentage of Hispanic workers (by 0.45 percent) in 1992.
} 
into blue-collar or service jobs. ${ }^{27}$ Of course, these results do not indicate whether Affirmative Action hiring is used more for such occupations, or whether Affirmative Action leads to more hiring into such occupations, or to the appearance thereof via title inflation (Smith and Welch, 1984). Given these questions, it is unclear whether it is always appropriate to control for occupation (or required skills), which generates only within-job estimates of Affirmative Action effects.

The fifth panel of Table 1 provides descriptive information on firm characteristics, broken down by whether or not Affirmative Action was used in recent hiring. Firms using Affirmative Action are much larger, have a significantly higher proportion of the workforce covered by collective bargaining, and are significantly more likely to be in the services industry. These firms also have higher percentages of black and Hispanic customers.

Finally, the sixth panel of Table 1 reports on the demographic characteristics of supervisors and respondents to the survey. We see that respondents - who are responsible for hiring - are more likely to be the opposite sex from the new hire in firms that report using Affirmative Action in hiring, although this is not true of supervisors. In the multivariate analyses that follow, we ask whether these characteristics of respondents or supervisors have any bearing on the results for outcomes over which respondents or supervisors exert some control - such as promotions and performance ratings.

\section{The Effects of Affirmative Action on Hiring of Women and Minorities}

Table 2 presents a multivariate descriptive analysis of the relationship between Affirmative Action hiring and the demographic group of the recent hire, based on logit or multinomial logit estimates of the association between Affirmative Action hiring and the demographic group of the recent hire, accounting - in different specifications - for differences in firm characteristics, in the

\footnotetext{
${ }^{27}$ This evidence is broadly consistent with Leonard's (1989) findings that Affirmative Action has created the most opportunities for white women in white-collar trainee positions, and for black females in managerial, sales, clerical, laborer, and white-collar trainee positions.
} 
occupational distribution of hires, and in job requirements. ${ }^{28}$ In each column, we report the estimated effects of Affirmative Action hiring on the probability that the hire was in the demographic group listed in the left-hand column, relative to the probability that the hire was in the omitted demographic group (i.e., the logit or multinomial logit coefficient estimates). The marginal effects on the probabilities are reported in square brackets.

We first look at aggregated demographic groups. Columns (1) and (1') report estimates for the probability that the recent hire was a minority or white female. In column (1), controls for city and year of hire, as well as firm characteristics (listed in Table 1) are included. The probability that a minority or female was hired is estimated to be significantly higher, by .03, when Affirmative Action is used in hiring. ${ }^{29}$ Column (1') adds controls for the occupations and job requirements listed in Table 1. Probably in part because Affirmative Action is used relatively more in occupations into which women are more likely to be hired, the association between Affirmative Action and hiring of minorities or females weakens slightly when we include these controls.

Columns (2) and (2') repeat estimates with the same control variables, but report estimates of multinomial logit models for the probability of a hire in each of the demographic groups identified in the data. The estimates in column (2') indicate that the probabilities that white females and black males are hired, relative to the probability that a white male is hired, are significantly higher when Affirmative Action is used in hiring; the hiring of black and Hispanic females appears to be

\footnotetext{
${ }^{28}$ In this table and all that follow, estimates are sample-weighted (as they were in Table 1). This has some bearing on the estimates because the effects are somewhat different for college educated and high-school educated workers, and the latter are overrepresented in the sample. Thus, the sample weighting produces more accurate "average" effects.

29"Minority or female" refers to white women, blacks, and Hispanics. All of the models estimated in the paper also included categories for Asian men and women. However, we do not focus on (or report) results for Asians, since most of the debate seems to be about the treatment of relatively disadvantaged subgroups of the population, a categorization which may not apply to Asians.
} 
unaffected. ${ }^{30}$ Comparing effects on probabilities to the means in Table 1 for each group, we see that Affirmative Action is associated with an increase of about ten percent (not ten percentage points) in the probability of hiring white women, and an increase of about 20 percent in the probability of hiring black men. Finally, the last row indicates that the probability that a white male is hired is lower by about 15-20 percent under Affirmative Action. ${ }^{31}$ Presumably, most of these white males are then hired in firms not using Affirmative Action; these firms likely pay less, among other reasons because they are smaller. ${ }^{32}$

These results, coupled with evidence of strengthened enforcement activity in 1989 and especially in 1993 (Anderson, 1996), suggest that Affirmative Action has real consequences for firm hiring behavior. We next turn to the more contentious issue of the relative qualifications and performance of women and minorities hired under Affirmative Action.

\section{Relative Qualifications and Performance of Affirmative Action Hires}

Having documented the associations between Affirmative Action and hiring of minorities and women, we now turn to the central question of this paper - whether Affirmative Action leads to the hiring of less-qualified women or minorities. Our general approach is to let $\mathrm{Q}$ be a measure of the qualifications or performance of the last worker hired, and to estimate equations of the form:

$$
\mathrm{Q}_{\mathrm{ijk}}=\alpha \mathrm{WM}_{\mathrm{ijk}} \cdot\left(1-\mathrm{AA}_{\mathrm{jk}}\right)+\beta \mathrm{D}_{\mathrm{ijk}} \cdot \mathrm{AA}_{\mathrm{jk}}+\gamma \mathrm{WM}_{\mathrm{ijk}} \cdot \mathrm{AA}_{\mathrm{jk}}+\delta \mathrm{D}_{\mathrm{ijk}} \cdot\left(1-\mathrm{AA}_{\mathrm{jk}}\right)+\theta \mathrm{X}_{\mathrm{j}}+\lambda Z_{\mathrm{k}}{ }^{\prime}+\epsilon_{\mathrm{ijk}}
$$

\footnotetext{
${ }^{30}$ See footnote 26 .

${ }^{31}$ We divide 0.05 or 0.06 by the average proportion of white males in non-Affirmative Action firms in Table 1 . Note that in columns (1) and (1'), the marginal effects reported for minorities or white females are smaller in absolute value than those for white males. This is because Asians are also included in the estimation, and their hiring appears to be boosted more by Affirmative Action.

${ }^{32}$ Further, if there is some job segregation by demographic characteristics, or if overall hiring at firms using Affirmative Action falls because of the policy, the wages of white males in non-Affirmative Action firms will be lower because of an outward labor supply shift.
} 
where AA is a dummy variable indicating that Affirmative Action was used in hiring, $\mathrm{D}$ is a vector of demographic dummy variables for women or minorities, WM is a dummy variable for white males, $\mathrm{X}$ is a vector of job characteristics, and $\mathrm{Z}$ a vector of firm characteristics; $\mathrm{i}, \mathrm{j}$, and $\mathrm{k}$ denote the last worker hired, the most recent job filled, and the firm, respectively. Note that we include separate intercepts for each demographic group distinguished by the Affirmative Action status of the firm, and no common intercept.

This specification provides us with a number of potential comparisons for estimating the effects of Affirmative Action in hiring. One interesting comparison is between women or minority hires in firms using Affirmative Action and white male hires in firms using Affirmative Action. The difference in $Q$ for this comparison is given by $(\boldsymbol{\beta}-\boldsymbol{\gamma})$. A second interesting comparison is between women or minority hires in firms using Affirmative Action and women or minority hires in firms not using Affirmative Action, which is captured by the difference $(\beta-\delta)$. A third comparison is between women or minority hires in firms using Affirmative Action and white male hires in firms not using Affirmative Action, which is measured by $(\beta-\alpha)$; this comparison may be relevant to those white male workers who might otherwise have been hired in firms using Affirmative Action had the policy not been in place.

With respect to the first two comparisons, in particular, there is the potential for misleading inferences to be drawn. For example, suppose that the estimate of $(\beta-\gamma)$ is a large negative number, indicating that women or minorities hired into firms using Affirmative Action are less qualified than white males hired into similar firms. However, there may be a similar shortfall in qualifications between women or minorities and white males in firms not using Affirmative Action; workers in nonAffirmative Action firms should then serve as a control group to pick up overall differences between minorities or women and white men. For example, Hispanics may be perceived as less qualified or 
perform less well because of language barriers, regardless of whether the firm into which they are hired uses Affirmative Action. Continuing with this example, this implies that to estimate the independent effects of Affirmative Action on differences between white male and Hispanic workers, we want to subtract off any shortfall in qualifications attributable to language in firms not using Affirmative Action, and to ask instead whether the shortfall is relatively larger in firms using Affirmative Action. In general, the shortfall in qualifications (or performance) in firms not using Affirmative Action is measured by $(\delta-\alpha)$, leading to the difference-in-differences estimate of $(\beta-\gamma)$ - $(\boldsymbol{\delta}-\boldsymbol{\alpha}) .{ }^{33}$ Thus, critics of Affirmative Action make a potential error if they base their criticisms only on observed shortfalls in qualifications at firms using Affirmative Action, rather than the net difference in these shortfalls between the two sectors.

Similarly, if the comparison $(\beta-\delta)$ indicates that women or minorities hired at firms using Affirmative Action are less qualified than similar workers hired at firms not using Affirmative Action, we have to ask whether there is a similar difference in qualifications between white males hired at firms using Affirmative Action and white males hired at other firms, because of differences between the two sets of firms that are common to all demographic groups; this leads to the same difference-in-differences estimator. ${ }^{34}$ However, the generally higher skills and qualifications in firms using Affirmative Action suggests that the difference-in-differences estimator is more relevant to the comparison between women or minorities and white males at firms using Affirmative Action. Table 3 summarizes the alternative estimates we present. ${ }^{35}$

\footnotetext{
${ }^{33}$ Note that the difference-in-differences estimator $(\beta-\gamma)-(\delta-\alpha)$ is equal to the difference between the first and third comparisons, $(\beta-\gamma)-(\beta-\alpha)$, plus the second comparison, $(\beta-\delta)$. Note also that this estimator does not distinguish between a larger difference in qualifications in firms using Affirmative Action that arises from lower standards for women or minorities, or higher standards for white men, relative to firms not using Affirmative Action.

${ }^{34}$ This estimator is $(\beta-\delta)-(\gamma-\alpha)$, which is equal to $(\beta-\gamma)-(\delta-\alpha)$.

${ }^{35} \mathrm{~A}$ relevant differences-in-differences estimate with respect to the difference $(\beta-\alpha)$ is (woman/minority AA hire vs. white male non-AA hire) - (woman/minority non-AA hire vs. white male non-AA hire). This estimate corresponds to
} 
There are three potential econometric problems with estimates of equation (1). First, we cannot be certain that the differentials associated with Affirmative Action do not reflect unmeasured job or firm characteristics that differ across firms that use Affirmative Action in hiring and hire minorities or women, and firms that use Affirmative Action but do not hire minorities or women i.e., unobserved characteristics that vary within the subset of firms using Affirmative Action in such a way as to be correlated with minority or female hiring. But, as noted above, the difference-indifferences estimator eliminates unobserved differences in job or firm characteristics by race or sex that are constant across firms that do and do not use Affirmative Action (or differences by Affirmative Action status that are constant across demographic groups). Without data on multiple hires for the same job in the same firm, we must simply make the assumption that unobserved job or firm characteristics are not correlated with the Affirmative Action-demographic group interactions (D·AA) as well as with qualifications, in order to identify relative differentials in qualifications among minorities or women hired under Affirmative Action.

Second, if the decision to use Affirmative Action is endogenous, then D·AA may be correlated with the error term. If firms with the smallest skill differentials between minorities and females, on the one hand, and white males, on the other, are most likely to embrace such hiring (since they may face the lowest costs from using Affirmative Action), our estimates may be biased in the direction of finding no differences in qualifications, relative to the estimates we would obtain from an exogenously-imposed policy (such as requirements on federal contractors). However, the correspondence between the patterns of reported use of Affirmative Action in our data and in Leonard's data (based on contractor status), coupled with the fact that firms in some industries are Action. However, Table 1 indicates that this is unlikely to be an issue. 
much more likely to be federal contractors than are firms in other industries, suggests that a good part of the variation in use of Affirmative Action is exogenous. Furthermore, the main goal of this paper is to evaluate the effects of Affirmative Action as it is used in practice, and not to evaluate the effects of an exogenously imposed Affirmative Action policy. For this question, the issue of self-selection into the sample using Affirmative Action is irrelevant. It becomes relevant, however, if we try to draw conclusions regarding, for example, the effects of eliminating Affirmative Action practices. As this discussion emphasizes, considerable caution must be exercised in drawing any such conclusions from our evidence, as the assumptions required to justify such conclusions may not hold in our data.

Finally, as discussed above, there is some ambiguity in the classification of firms using Affirmative Action. Though we believe it is small, any misclassification of firms is likely to bias the results towards finding no impact of Affirmative Action. Since for many demographic groups our evidence points to no impact, the results must be interpreted cautiously, pending development of superior data sources to re-examine some of the questions we consider in this paper.

\section{Educational Qualifications}

The qualification we can most easily identify with workers is their education. Table 4 reports alternative simple differences and difference-in-differences estimates for years of education of the last worker hired. The estimates in Panel A are based on specifications that include only city and year dummy variables and firm characteristics as control variables. The estimates in column (1) measure $(\beta-\gamma)$, the differences between women or minorities and white males hired at firms using Affirmative Action. For all five groups, the educational level of women or minority Affirmative Action hires is significantly lower than that of white males hired into similar firms; the differential is less than one-half year for white females, but about one and one-half years for blacks, and two and 
one-half years for Hispanics. ${ }^{36}$ However, the estimates of $(\boldsymbol{\beta}-\boldsymbol{\alpha})$ in column $(3)$ indicate that these educational shortfalls also appear - although to a lesser extent - between women and minorities hired in firms using Affirmative Action, and white males hired in firms not using Affirmative Action. At the same time, the estimates in column (2) indicate that, with the exception of Hispanic males, there are negligible differences between women and minorities in firms using Affirmative Action and in firms not using Affirmative Action. The combined evidence implies that the educational shortfalls in column (1) overstate the shortfalls that can be attributed to Affirmative Action hiring. This is reflected in the difference-in-differences estimates in column (4), which indicate considerably smaller educational shortfalls of women and minorities attributable to Affirmative Action hiring. The differentials for white females and blacks are small and insignificant, while only those for Hispanics (especially men) remain large and significant.

In Panel B we present the same types of estimates, but including controls for occupation and job requirements in equation (1). We know from Tables 1 and 2 that the apparent effects of Affirmative Action in shifting the demographic composition of recent hires is weaker within than across occupations; it therefore may be more appropriate to look at relative educational attainment of newly hired workers within our broadly-defined occupations, and controlling for job requirements. At some level, the relevant policy question concerns the relative skills of individuals hired to do the same job; if minorities and females hired under Affirmative Action are matched to jobs that are appropriate for their skill levels, the within-job estimates might be most appropriate. On the other hand, occupation and job requirements likely reflect the characteristics of the worker hired as well as the job, in which case we may be over-controlling by including them as independent variables; that is,

\footnotetext{
${ }^{36}$ This evidence is broadly consistent with lower education and higher dropout rates of Hispanics (Hauser and Phang, 1993).
} 
Affirmative Action may lead to the hiring of less-skilled women or minorities who are then allocated to less-demanding jobs. As a consequence, firms using Affirmative Action may have created more unskilled job slots than they would have in the absence of these policies, thus lowering the overall skill level of their workforce. Given these ambiguities regarding the choice of specification, we think it best to present both types of evidence.

The qualitative conclusions in Panel B are very similar to those in Panel A. The only notable difference is that the education differentials between women or minority workers hired by firms using Affirmative Action and other workers are smaller, especially for Hispanic males, both in the simple differences and the difference-in-differences estimates. The decline in the magnitude of the shortfall for Hispanic males hired by firms using Affirmative Action when we control for job requirements suggests that to some extent they are allocated to jobs which require less education.

Given the results in Table 2 indicating that hiring of Hispanics is not boosted by Affirmative Action, it is perhaps a bit difficult to interpret the lower qualifications of Hispanics as resulting from Affirmative Action hiring. However, the Table 2 results are based on cross-sectional data, rather than panel data, so it is possible that those firms that use Affirmative Action would have otherwise hired even fewer Hispanics. To shed some additional light on this question, we analyzed data on the percentage of applicants at the firm accounted for by each demographic group, as reported by the respondent. These reveal that, in firms using Affirmative Action, the percentage of applications from blacks is higher (by roughly two percentage points each) than in firms not using Affirmative Action, while this percentage is lower for Hispanics (by 0.8 percentage points).$^{37}$ Given their higher overall skill needs and lower application rates from this group, firms that use Affirmative Action may have to

\footnotetext{
${ }^{37}$ The lower percentage of applicants from Hispanics in these firms is not significantly different from zero, but it is significantly different from the fraction of blacks applying.
} 
be less selective in hiring Hispanic applicants. ${ }^{38}$

An alternative approach to the issue of educational qualifications is to ask whether minorities or women hired under Affirmative Action are less qualified relative to the educational requirements of the job, rather than simply relative to white males. We refer to this outcome as indicating that the employee is "underqualified," rather than "less qualified." For example, if Hispanics are sufficiently qualified for the jobs they hold, while white males are either overqualified or allocated to more demanding jobs, then the criticism of Affirmative Action on the grounds of lower educational levels of Hispanics (as in Table 4) would be blunted. Conversely, while we find no evidence suggesting that white women or blacks hired under Affirmative Action have relatively less education than white males, they might be more underqualified relative to the jobs that they hold.

To examine this question, we use information on the educational requirement for the job reported by the employer, and estimate logit models for whether the individual hired had less than the reported required amount of education. There is some ambiguity in the coding of this dependent variable, since employers were asked whether a college degree was required, without specifying whether this was an Associate's or Bachelor's degree. We assume that they were referring to the latter. $^{39}$

The results are reported in Table 5; the control variables are the same as in Table 4. In column (1) in Panel A, the positive signs of the estimates indicate that for all groups, women or minorities hired under Affirmative Action are relatively more likely to be underqualified than white males hired into firms using Affirmative Action. However, the estimated coefficients are significant

\footnotetext{
${ }^{38}$ One reason for the lower application rate of Hispanics at firms using Affirmative Action might be that Hispanic immigrants are more likely to work in smaller establishments that are owned or operated by co-ethnics, especially in Los Angeles.

${ }^{39}$ There are very few cases in the sample of workers being hired into jobs requiring college degrees that did not have at least an Associate's degree.
} 
only for black females (at the five-percent level) and Hispanic females (at the ten-percent level). In column (3), we find a significantly higher probability that black males hired under Affirmative Action are more likely to be underqualified, relative to white males in firms not using Affirmative Action. However, in this table the column (2) estimates also indicate that some groups of women or minorities hired under Affirmative Action are underqualified relative to comparable workers in firms not using Affirmative Action. As a result, the difference-in-differences estimates are quite similar to those in the other columns, although now the only significant evidence of underqualification of women or minorities hired under Affirmative Action is for black females. Panel B, where we add the occupation and job controls, leads to similar conclusions. ${ }^{40}$

\section{Other Measures of Qualifications}

In addition to looking at educational qualifications, we can use the data on non-educational job requirements of recent hires to assess further whether minorities or women hired under Affirmative Action are less qualified. Although these data refer to the job and not the worker, they may contain some information on worker qualifications, although they may tell us more about the skill requirements of jobs to which various groups of workers have been matched than about skill differences among workers within jobs.

As Table 1 indicates, we have data on seven job requirements. To provide a summary measure, we construct the dependent variable used in Table 6 simply as the number of requirements of the job held by the recent hire. The estimates in column (1) indicate significant shortfalls of black and Hispanic males hired in firms using Affirmative Action relative to white males in similar firms. However, these shortfalls also exist - although they are somewhat smaller - relative to white males

\footnotetext{
${ }^{40}$ Because this specification looks at education relative to educational requirements, it is not surprising that controlling for other job characteristics has little influence on the estimates.
} 
hired into firms not using Affirmative Action, as shown in column (3), but do not appear in comparing women and minorities in the Affirmative Action and non-Affirmative Action sectors, as shown in column (2). On net, therefore, the difference-in-differences estimates for black and Hispanic males reveal much smaller differentials attributable to Affirmative Action, significant only for Hispanic males. In addition, the difference-in-differences estimates indicate that Hispanic women hired in firms using Affirmative Action are in jobs with relatively more requirements, indicating that Hispanic women may possess other skills or qualifications that offset their lower educational qualifications. In Panel B, when occupation controls are added, the differentials for black and Hispanic men are reduced, with the difference-in-differences estimate no longer significant for the latter group. Of course this may just reflect the fact that much of the variation in job requirements occurs across rather than within occupations.

\section{$\underline{\text { Job-Related Outcomes }}$}

The results in the preceding sections provide some evidence of relatively lower educational or skill qualifications of blacks and Hispanics hired under Affirmative Action. But there remains the question of whether the shortfalls in these two observable measures of qualifications imply inferior performance on the job. If they do not, then there is perhaps no reason to be concerned with the apparent lower qualifications of minorities hired under Affirmative Action. ${ }^{41}$

Consequently, in this subsection we look at three employment outcomes that should be related to actual job performance: starting wages, current wages, and promotions. Looking at this broader set of job-related outcomes is useful for another important reason - namely, educational levels and job requirements are only a subset of the many dimensions along which a worker's qualifications can be

\footnotetext{
${ }^{41}$ As an example, Bloch (1994) discusses James v. Stockham Valves and Fittings Company, in which an employer claimed that formal education requirements for manual laborers led to hiring of more whites than blacks. But the court ruled that education was unrelated to job performance.
} 
measured. Measures such as wages and promotions should, if they are related to productivity, provide more of a summary or "sufficient" statistic for a worker's qualifications. A potential objection, however, is that the same pressures that may lead to the hiring of less-qualified workers under Affirmative Action may also lead employers to pay and promote women and minorities at a rate that is more than commensurate with their productivity, in which case wages and promotions would not be useful as measures of their relative job performance. ${ }^{42}$

To obtain a more independent measure of worker performance in these jobs, we use a rating of the worker's job performance (measured on a scale of one to 100) elicited from the person interviewed. ${ }^{43}$ The survey also asked for the supervisor's rating of the typical new hire into the job, which lets us standardize across firms and jobs by looking at the deviation of the new hire's performance rating from the usual or typical rating. If the performance ratings were the product of a formal evaluation procedure that is used to set wages and determine promotions, they might be contaminated in the same way as data on wages and promotions (as employers might feel constrained to manipulate performance ratings to back up their wage and promotion decisions). However, these ratings are informal and unrelated to any actual pay and promotion decisions, and survey respondents were promised full confidentiality. Therefore, the ratings seem likely to provide an unbiased measure of a worker's true job performance.

However, even the standardized performance ratings are likely to be measured with considerable error. If the measurement error is random with respect to true performance and the independent variables, it should lead to larger standard errors on the estimated coefficients.

\footnotetext{
${ }^{42}$ The wage and promotion results might still be of some interest, since there is virtually no empirical evidence to date on the relationship of Affirmative Action to these outcomes.

${ }^{49}$ A similar variable is used in the EOPP Survey (e.g., Barron, et al., 1989) and a more recent, similar survey of members of the National Federation of Independent Businesses (Bishop, 1993).
} 
However, the estimated signs of these coefficients should not be biased. Thus, if we fail to find negative effects of Affirmative Action on these ratings, it would be difficult to interpret such findings as stemming solely from measurement error.

\section{$\underline{\text { Wages }}$}

Regressions for logs of starting and current wages are reported in Panels A and B of Table 7. In addition to the firm, occupation, and job requirement controls, we also add standard human capital controls (education and age to both sets of equations, and tenure to the equation for current wages). ${ }^{44}$ As a means of assessing the reliability of the data, it is worth noting that wage differentials between women or minorities and white males in firms not using Affirmative Action, which can be calculated from the estimates in column (3) minus the estimates in column (2), indicate significantly lower wages paid to women and minorities. The estimated differentials are -.16 for white women, -.17 for black men, -.25 for black women, -.31 for Hispanic men, and - .30 for Hispanic women.

Turning to the three alternative comparisons for women or minority workers in firms using Affirmative Action, column (1) indicates that the wage differentials between these workers and white males in similar firms are considerably smaller than the wage differentials in firms not using Affirmative Action, noted above. ${ }^{45}$ In fact, for black men the wage differential is erased. Because the wage differentials compared with white males in firms not using Affirmative Action are somewhat larger, as reported in column (3), and the differences between women and minorities in the two types of firms are small, as reported in column (2), the difference-in-differences estimates in column (4) indicate that Affirmative Action raises the relative wages of women and minorities, although most

\footnotetext{
${ }^{44}$ One might object that by controlling for differences in qualifications, we bias the results against finding poorer performance, as measured by wages (or promotions). However, the results reported in Table 7 turned out to be insensitive to the inclusion of these variables.

${ }^{45}$ Leonard (1990) reports similar evidence indicating that relative wages of minority to white males are higher in cities and industries with high proportions of employment in establishments subject to Affirmative Action.
} 
groups still earn less than comparable white males in firms using Affirmative Action; the increase is substantial for black and Hispanic men, on the order of 20 percent. ${ }^{46}$ The results are quite similar for starting and current wages, indicating no differences in wage growth. ${ }^{47}$

\section{Promotions}

Panel C of Table 7 reports logit estimates of equations for whether the newly hired worker was promoted. ${ }^{48}$ The independent variables are the same as in the other panels, with the exception of an additional specification including controls for whether the race or sex of the supervisor differed from that of the worker. The results in column (1) suggest that the probability of promotion for blacks and Hispanics hired in firms using Affirmative Action is higher than for white males in similar firms, although the differential is statistically significant only for Hispanic females. The differencein-differences estimates in column (4) convey the same result. Finally, again subtracting the estimates in column (2) from those in column (3), we see that in firms not using Affirmative Action, promotion probabilities are lower for each of the five groups of minorities or women. However, in contrast to wages, the estimates suggest that the negative promotion differentials for Hispanics and blacks in these firms is reversed in firms using Affirmative Action. This is so despite the earlier evidence that blacks and Hispanics are relatively less qualified in terms of educational attainment.

\footnotetext{
${ }^{46}$ Table 1 indicates that the percentage of the workforce covered by collective bargaining is higher in firms using Affirmative Action. However, the relatively higher wages paid to women and minorities in such firms do not appear to be attributable to the well-documented tendency for race and sex differentials in wages to be lower among union workers. We reestimated the models adding a set of interactions between the demographic dummy variables $D$ and two alternative measures of unionization: the percentage covered by collective bargaining; and a dummy if this percentage was greater than zero. The relatively higher wages paid to women or minorities in firms using Affirmative Action, based on the difference-in-differences estimates, did not diminish in this augmented specification. In fact, in these data the effects of unions appear to be reversed, with the signs of the estimated coefficients of the demographic dummy variable-union interactions negative (although generally not significant). Part of the problem may be that we do not know the union status of the specific recent hire to whom the data refer.

${ }^{47}$ This was confirmed by estimating similar regressions for the change between the starting and current wage. None of the estimated coefficients of the Affirmative Action-demographic group interactions were statistically significant.

${ }^{48} \mathrm{~A}$ limitation of the promotions variable is that median tenure with the employer is roughly two to three months in our sample. The proportion of workers promoted is only .08 .
} 


\section{Performance Ratings}

Given our uncertainty over whether the wage and promotion results reflect better performance of blacks and Hispanics, or preferential treatment, we turn in Table 8 to the performance rating regressions, in which the dependent variable is the measured rating minus the typical rating. We report results including only the firm (and city and year) controls in Panel A, and adding in the occupation, job requirement, and other controls in Panel B. The estimates in column (1) indicate that black females hired under Affirmative Action obtain higher performance ratings than white males hired in similar firms, with the differential significant at the ten-percent level. The evidence for white females, black males, and Hispanic females also indicates that their performance is not lower than that of white males in similar firms. On the other hand, the performance ratings of Hispanic males at these firms are significantly lower.

The estimates in column (3) suggest that the differentials between each group of women or minorities and white males in firms that do not use Affirmative Action are similar to the differentials in firms that use Affirmative Action. But the estimates in column (2) also indicate that similar differentials exist between these groups of women or minorities hired at the two types of firms. As a result, the difference-in-differences estimates in column (4) are quite similar to those in column (1); the only difference is that the relative performance of black females hired in firms using Affirmative Action is now more strongly positive. The evidence is very similar in Panel B, when the more extensive set of controls is added..$^{49,50}$

\footnotetext{
${ }^{49}$ If use of Affirmative Action in hiring is not exogenous, it is possible that the relatively positive ratings given to blacks in firms using Affirmative Action might reflect relatively favorable views of minorities at firms that have chosen to use Affirmative Action. But it is unclear why this would be true for many groups but not Hispanic males. Our controls for the racial composition of customers and for the race/gender of the respondent should also help to control for such factors. We also note that our job requirement controls include information on customer contact, where immigrant Hispanics or Asians might be at some disadvantage relative to native-born whites and blacks.

${ }^{50}$ The estimated coefficients of the demographic dummy variables (measuring performance rating differentials in firms not using Affirmative Action) were all statistically insignificant, although they were positive for all groups except white
} 
Thus, the evidence for Hispanics tells a relatively consistent story, especially for the men. We generally find that Hispanic men and women hired under Affirmative Action are less qualified in terms of education; and at least the men are matched to less-demanding jobs and get worse performance ratings. ${ }^{51}$ On the other hand, while we find some evidence that blacks are less qualified in terms of education, we find no such evidence in their performance ratings, which (like their wage and promotion rates) are relatively higher in these firms than elsewhere. And for white females, who appear to be the primary beneficiaries of Affirmative Action (in terms of numbers of hires), we find virtually no evidence of weaker (or stronger) qualifications or performance..$^{52,53}$

women. The estimated coefficients of the dummy variables for different race or sex of the respondent or supervisor indicated that supervisors or respondents of the opposite sex resulted in performance ratings that were significantly higher, by about two points, whereas supervisors or respondents of the opposite race resulted in ratings that were lower by about one to two points (significantly so for supervisors of the opposite race).

${ }^{51}$ Although Hispanics in this sample are heavily concentrated in Los Angeles (with 70 percent of the newly hired Hispanics being located there), the finding of low performance ratings for Hispanic men is not unique to Los Angeles; if anything, the negative difference-in-differences estimates for Hispanic males in Los Angeles were somewhat smaller than those in other cities.

\footnotetext{
${ }^{52}$ When we add these performance measures to the current wage equations in Table 7 , we generally find that they generate positive and significant effects on wages. But the various race/gender differentials presented there are little changed by their inclusion. On one hand, this suggests that the relatively higher wages paid to women and minorities hired under Affirmative Action may reflect preferential treatment. On the other hand, these results are based on using the performance ratings as an independent variable; the presumed measurement error in these ratings inhibits our ability to ask whether performance ratings explain these higher wages.
}

${ }^{53}$ One potential problem with the standardized performance ratings is that when we look at a worker hired by a firm using Affirmative Action, the typical rating that is subtracted off may also apply to an Affirmative Action hire. In this case, the standardization may erase any relative differences in performance between Affirmative Action and nonAffirmative Action hires, leading the difference-in-differences estimate of the effect of Affirmative Action on performance to be zero. To examine this possibility, we re-estimated the equations in Table 8 using the raw performance ratings. The column (4) estimates using the raw ratings were not generally further from zero than the corresponding estimates in Table 8, suggesting that standardization does not force the estimated effects of Affirmative Action to be zero. In fact, the only substantive change was that the relative performance shortfall of Hispanic men was erased. This occurred because the estimated difference with respect to Hispanic males in firms not using Affirmative Action fell to zero, in contrast to an estimated difference of -5.94 in Table 8; this indicates that the typical rating of jobs into which Hispanic males are hired is substantially higher in Affirmative Action firms, which is a reason to standardize the performance ratings, and stands in contrast to the potential problem that typical ratings in firms using Affirmative Action are biased towards the ratings of the Affirmative Action hire to whom the data refer, thus obscuring lower ratings of such hires. 


\section{Disaggregated Results}

The above results address average effects for each of the demographic groups considered. But these averages might mask differences across subgroups within the broader category. In particular, we disaggregate the data set by establishment size, based on the claim by some researchers that Affirmative Action has different effects at large and small establishments (e.g., Bloch, 1994). Affirmative Action effects may differ in large and small establishments because establishments of different sizes use different methods to implement the policy, or because they face different costs of compliance or non-compliance. Table 9 therefore present results for performance ratings, as well as the hiring shifts associated with Affirmative Action, breaking down the results for establishments with less than (or equal to) 100 and more than 100 workers.

The estimates in column (1) parallel the multinomial logit estimates in column (2') of Table 2 of the association of Affirmative Action hiring with the demographic group of the worker hired. In Panel A, which looks at small establishments, the results largely parallel those in Table 2, as the only significant associations are a higher likelihood that a white female or black male is hired. In Panel B, in contrast, which looks at large establishments, the largest effects appear to be negative associations with the likelihood of hiring black females or Hispanics.

To some extent, this reflects the tendency of large firms to hire minorities (especially blacks) in large numbers regardless of their use of Affirmative Action (Holzer, 1996b). There are also some differences in observable characteristics between large firms that use Affirmative Action and those that do not. In particular, large establishments using Affirmative Action are more likely to be in the service sector, while those not using Affirmative Action have a greater tendency to be in wholesale and retail trade and to be located in central cities. In addition, application rates from blacks and Hispanics are relatively higher in firms not using Affirmative Action. Thus, it does not appear that 
Affirmative Action boosts the hiring of women or minorities relatively more in large than in small establishments; in fact, the opposite may even be the case, as the estimated effect of Affirmative Action on the probability that a white male is hired is actually positive in large establishments. ${ }^{54}$ The results for performance ratings, in columns (2)-(5), are quite striking. In particular, the difference-in-differences estimates provide some evidence that in large establishments (over 100 workers) women and minorities hired under Affirmative Action receive lower performance ratings than white men hired into similar firms, with the differentials significant for white females, black males, and Hispanic males (for whom the effect is quite large, equal to about one standard deviation of the standardized performance rating). ${ }^{55}$

However, note that the lower relative performance ratings of women and minorities in large establishments using Affirmative Action do not appear in any of the simple differences (with the exception of Hispanic males in column (3)); in fact, most are positive, and with the exception of Hispanic males, all are small. This occurs because the relative differences stem from the lower ratings for white males in non-Affirmative Action firms (column (3)), rather than lower ratings for women and minorities in firms using Affirmative Action (column (1)). ${ }^{56}$

\footnotetext{
${ }^{54}$ This qualitative result did not change if we included measures of the percentage of applicants in each demographic group, for the subsample and for the subset of demographic groups (black males, black females, and Hispanics) for whom these measures are available. However, these data on applicants are probably very noisy, because they are firm-wide, and do not refer specifically to the job in which the recent hire occurred.

${ }^{55}$ Since the survey respondent was identified as the person who had hired the last worker, it is likely to be the owner or manager in small- and medium-sized companies; this person should also be able to speak knowledgeably about a worker's job performance. In large companies, these functions are more likely to be separated, perhaps suggesting more error in the performance measures for these observations. However, at least insofar as the measurement error is random, this cannot explain the large differentials in establishments employing more than 100 workers.

${ }^{56}$ This finding speaks to a potential source of bias in the estimation of equation (1) when we look at performance ratings. If firms that adopt Affirmative Action by choice tend to be those that are favorably disposed towards women or minorities, we might expect higher ratings of women or minorities in such firms, leading to a positive correlation between the error term and the D-AA interactions. We would expect this problem to be more severe in small establishments, where the use of Affirmative Action is more likely to be voluntary. Although this source of bias would lead us to expect larger recorded performance shortfalls for women and minorities hired under Affirmative Action in large establishments, we would expect this to act through higher ratings for women or minorities in small establishments using Affirmative
} 
In addition, we emphasize that recent hires into these large establishments represent less than one-third of the total sample, and for most demographic groups the results are reversed in small establishments, although the differentials are smaller. ${ }^{57}$ Thus, for most women and minorities, job performance relative to white males is roughly the same whether or not Affirmative Action is used in hiring.

\section{Conclusion}

We use micro-level data on employers and employees to investigate whether minority or female employees hired under Affirmative Action procedures are less qualified, relative to other groups of workers. Our measures of qualifications include educational attainment of the workers hired (in absolute levels and relative to job requirements), skill requirements on the job, and a variety of outcome measures that presumably are linked to worker performance on the job. The analysis is based on data from a new survey of over 3,200 employers in four major metropolitan areas in the U.S.

On average, we find some evidence that minority employees hired under Affirmative Action have lower educational attainment, and are somewhat more likely to fall short of formal educational "requirements" on these jobs when they are hired, although we find no such evidence for white females hired under Affirmative Action. However, for blacks, at least, the shortfalls in education of workers hired at firms using Affirmative Action are not much larger than those at firms not using Affirmative Action.

Action, rather than through lower ratings for white males in large establishments not using Affirmative Action, as we find here. Thus, it appears that we have to consider other explanations of the differences in results by size of establishment.

${ }^{57}$ If we make the sample of large establishments bigger by choosing a smaller size cut-off (such as 50 ), the negative performance differentials fall and become insignificant for all groups except Hispanic males. 
We speculate that the perception that Affirmative Action leads to preferential treatment of women and minorities is based on a simple comparison of these groups with white males in firms using Affirmative Action. In these firms, it is not inaccurate for critics of Affirmative Action to assert that women or minorities are less qualified (in terms of education) than white males. However, the difference-in-differences analysis suggests that this shortfall to some extent reflects an economywide shortfall in educational attainment among minorities. That is, the gap in qualifications in the firms or sector using Affirmative Action does not necessarily imply that Affirmative Action is responsible for the gap; our evidence suggests that, to a large extent, it is not.

When we consider measures of outcomes for workers in these jobs, we find that minorities and females hired under Affirmative Action do relatively well. On average, their wages are relatively higher, as are their probabilities of promotion. But since these outcomes might themselves be driven by Affirmative Action policies, and not just by the performance of the workers, we also consider employers' ratings of employee performance as an additional outcome measure. These measures are subjective, and comparisons across employers and jobs are likely to be plagued by considerable noise and by the lack of a uniform standard; we therefore adjust the ratings for the employer's rating of the "typical" worker in the same job. The results show that ratings of white female or black employees in firms using Affirmative Action are generally at least as high as those of other comparable workers. These results are reversed only for Hispanic men, who receive significantly lower performance ratings (although this finding must be tempered by the fact that Affirmative Action does not appear to boost the hiring of Hispanic men in this sample).

Taken together, the results of this paper suggest that critics of Affirmative Action may be right in pointing to some shortfalls in qualifications among women or minorities hired under Affirmative Action. However, these critics may be focusing too narrowly on one or two easily- 
observable measures of qualifications that are not the only predictors of what is ultimately the most important measure - job performance. Our results suggest that most women or minorities hired under Affirmative Action make up in some way - presumably through qualifications or skills other than those measures we observe - for the educational shortfalls in qualifications that we find. Thus, there may be some redistribution of employment away from white males towards minorities and females at firms using Affirmative Action, but there does not appear to be substitution of less-able women or minority workers for more-able white male workers.

When we disaggregate our sample by establishment size, we find some evidence that in large establishments (over 100 workers) women and minorities hired under Affirmative Action are relatively less qualified and receive lower performance ratings than white men hired into similar firms. However, we do not attach too much importance to these results for a number of reasons: recent hires into these large establishments represent less than one-third of the total sample; for most demographic groups the results are reversed in small establishments (although the differentials are smaller); the relatively larger gap between women or minorities and white males in firms using Affirmative Action is driven by lower ratings of the latter in non-Affirmative Action firms, rather than lower ratings of the former in Affirmative Action firms; and, Affirmative Action does not appear to boost hiring of women or minorities in the large establishments in our data set.

Therefore, we interpret the overall evidence as indicating that most groups of women and minorities hired under Affirmative Action perform their jobs roughly as well relative to white males as do those hired in firms that do not use Affirmative Action. The average effects indicated by the full sample results - which arguably are most relevant to evaluating the effects of the policy - support the conclusion that there is essentially no performance shortfall among most groups of women and minorities hired under Affirmative Action. 
This does not necessarily imply that there are no costs to the use of Affirmative Action. One possibility is that these firms hire relatively more less-skilled workers than they would in the absence of Affirmative Action, which might entail some cost in efficiency. Another is that the same number of less-skilled workers are hired as before, but that there is relatively more redistribution of employment away from less-skilled white males within these firms. Without panel data on firms both before and after their use of these procedures, it is impossible to distinguish among these interpretations.

We should also note a number of further caveats with respect to these findings. Given the data that we have, we are only able to estimate the effects of Affirmative Action on the last worker hired in each firm, which is not necessarily a representative sample of all employees hired under these procedures. We are also not able to compare different hires into comparable jobs within each firm. The focus on recent hires also forces us to consider only short-term outcomes for a sample of employees with very low job tenure. Finally, our self-reported measure of use of Affirmative Action may not allow us to define the relevant set of firms or activities as clearly as in those studies that use more objective measures, such as federal contractor status (although we have argued that our measure appears to mimic more objective measures quite well, and could conceivably be preferable).

Despite these caveats, we believe that our data provide useful information on the effects of Affirmative Action, by providing the first micro-level evidence linking Affirmative Action to worker qualifications and performance. We interpret the data as indicating that, for the most part, Affirmative Action does not lead to the hiring of minorities or women with substantially lower qualifications or weaker job performance. 


\section{References}

Altonji, Joseph and Charles Pierret. 1996. "Employer Learning and the Signaling Value of Education." National Bureau of Economic Research Working Paper No. 5438.

Anderson, Bernard E. 1996. "The Ebb and Flow of Enforcing Executive Order 11246." American Economic Review Papers and Proceedings, Vol. 86, No. 2, May, pp. 298-301.

Badgett, M.V. Lee. 1995. "Affirmative Action in a Changing Legal and Economic Environment." Industrial Relations, Vol. 34, No. 4, October, pp. 489-506.

Barron, John, Mark Berger and Dan Black. 1994. "Employer Search, Training, and Vacancy Duration." Mimeo, University of Kentucky.

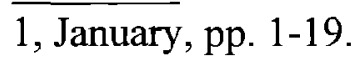

Bergmann, Barbara R. 1989. “Does the Market for Women's Labor Need Fixing?” Journal of Economic Perspectives, Vol. 3, No. 1, Winter, pp. 43-60.

Bishop, John. 1993. "Improving Job Matches in the U.S. Labor Market." Brooking Papers on Economic Activity: Microeconomics, 1, pp. 335-90.

Bloch, Ferrel. 1994. Anti-Discrimination Law and Minority Employment (Chicago: University of Chicago Press).

Bobo, Lawrence and Ryan Smith. 1994. "Antipoverty Policy, Affirmative Action, and Racial Attitudes." In S. Danziger, G. Sandefur and D. Weinberg eds. Confronting Poverty: Prescriptions for Change. Cambridge MA: Harvard University Press.

Cain, Glen. 1986. "The Economic Analysis of Labor Market Discrimination: A Survey." In O. Ashenfelter and R. Layard eds. The Handbook of Labor Economics. Amsterdam: North-Holland.

Carter, Stephen. 1991. Reflections of an Affirmative-Action Baby. New York: Basic Books.

Coate, Stephen and Glenn Loury. 1993. "Will Affirmative Action Policies Eliminate Negative Stereotypes?" American Economic Review. Vol. 83, no. 5, pp. 1220-1240.

Epstein, Richard A. 1992. Forbidden Grounds: The Case Against Employment Discrimination Laws Cambridge, MA: Harvard University Press.

Fix, Michael and Raymond Struyk. 1994. Clear and Convincing Evidence. Washington D.C.: Urban Institute Press.

Glazer, Nathan. 1975. Affirmative Discrimination: Ethnic Inequality and Public Policy. New York: Basic Books. 
Gold, Michael Evan. 1993. An Introduction to the Law of Employment Discrimination, ILR Bulletin 68. Ithaca, NY: ILR Press.

Hauser, Robert and Samuel Phang. 1993. "Trends in High-School Dropout Rates Among White, Black, and Hispanic Youth: 1977-89." Institute for Research on Poverty Discussion Paper.

Holzer, Harry J. 1996a. What Employers Want: Job Prospects for Less-Educated Workers. New York: Russell Sage Foundation.

1996b. "Employer Hiring Decisions and Antidiscrimination Policy." In R. Freeman and P. Gottschalk eds. Demand-Side Strategies for Low-Wage Labor Markets. New York: Russell Sage Foundation.

1995. "Employer Skill Needs and Labor Market Outcomes Across Groups." Russell Sage Foundation Working Paper.

Kane, Thomas. 1995. "Racial Preferences in College Admissions." Mimeograph, Harvard University.

Kling, Jeffrey. 1995. "High Performance Work Systems and Firm Performance." Monthly Labor Review. May, Vol. 118, No. 5.

Leonard, Jonathan S. 1984. "Anti-Discrimination or Reverse Discrimination: The Impact of Changing Demographics, Title VII and Affirmative Action on Productivity." Journal of Human Resources, Vol. 19, pp. 145-74.

1990. "The Impact of Affirmative Action Regulation and Equal Opportunity Law on Black Employment." Journal of Economic Perspectives, Vol. 4, No. 4, Fall, pp. 47-64.

. 1989. "Women and Affirmative Action." Journal of Economic Perspectives, Vol. 3, No. 1, Winter, pp. 61-76.

Loury, Linda Datcher and David Garman. 1995. "College Selectivity and Earnings." Journal of Labor Economics. Vol. 13, No. 2, pp. 289-308.

Lipset, Seymour Martin and William Schneider. 1978. "The Bakke Case: How Would It Be Decided at the Bar of Public Opinion?" Public Opinion, March-April, pp. 38-48.

Neumark, David. "Sex Discrimination in Restaurant Hiring: An Audit Study." Quarterly Journal of Economics, forthcoming.

Oettinger, Gerald. 1996. "Statistical Discrimination and the Early Career Evolution of the BlackWhite Wage Gap." Journal of Labor Economics, Vol. 14, No. 1, pp. 52-78.

Rodgers, William M., and William E. Spriggs. 1996. “The Effect of Federal Contractor Status on Racial Differences in Establishment-Level Employment Shares: 1979-1992." American Economic Review Papers and Proceedings, Vol. 86, No. 2, May, pp. 290-293. 
Smith, James and Finis Welch. 1984. "Affirmative Action and Labor Markets." Journal of Labor Economics, Vol. 2, April, pp. 269-301.

Sowell, Thomas. 1990. Preferential Policies: An International Perspective. New York: W. Morrow. 
Worker demographic characteristics:

White male

White female

Black male

Black female

Hispanic male

Hispanic female

\section{Worker education:}

\section{Drop out}

GED

High school graduate

Trade school or some college

AA degree

Bachelor's degree

Some graduate school

Graduate degree

Job requirements:

College degree

References

Vocational training

Specific experience

Customer contact

Reading/writing

Math

Computer

Occupation:

Management/professional

Sales

Clerical

Agricultural

Crafts

Operative

Labor

Service

\section{Firm characteristics:}

Employer size

Central city

Non-central city MSA

Percentage of workforce

covered by collective bargaining

Percentage of customers black

Percentage of customers Hispanic

Construction

TCPU

Wholesale trade

Retail trade

FIRE

Services

Public

Nondurables manufacturing

Durables manufacturing

Respondent and supervisor characteristics: Respondent's sex different from worker's sex Respondent's race different from worker's race Supervisor's sex different from worker's sex Supervisor's race different from worker's race
Jobs Filled Using Affirmative Action

Mean Std. Error

(1)

(2)

.24
.40
.09
.08
.07
.06

.01

.02

.01

01

.01

.01

$.03 \quad .0$

$.002-001$

$.30 \quad .01$

$22-01$

$.04-.01$

26

$.01-.003$

10

.01

.85

.33

.81

.46

.72

.73

.75

68

.63

.30

.13

.32

.01

.04

.08

.03

.09

572.1

.26

.16

$19.5 \quad 1.11$

19.5

13.7

.01

.07

.06

.11

.08

.08

.02

.10

.10

$\begin{array}{ll}.50 & .02 \\ .37 & .02 \\ .62 & .02 \\ .29 & .01\end{array}$

\section{Jobs Filled Not Using Affirmative Action}

Mean Std. Error

(3)

(4)

$\begin{array}{ll}.30 & .01 \\ .33 & .01 \\ .08 & .01 \\ .09 & .01 \\ .10 & .01 \\ .06 & .01\end{array}$

$.06 \quad .01$

$.003 \quad .001$

$.38 \quad .01$

$.22 \quad .01$

$.04 \quad .005$

$\begin{array}{ll}.17 & .01\end{array}$

$.02 \quad .004$

$\begin{array}{ll}.06 & .01\end{array}$

$\begin{array}{ll}.74 & .01\end{array}$

$.18 \quad .01$

$.73 \quad .01$

$.41 \quad .01$

$\begin{array}{ll}.62 & .01\end{array}$

$.72 \quad .01$

$\begin{array}{ll}.65 & .01\end{array}$

$\begin{array}{ll}.66 & .01\end{array}$

$.52-.01$

$.25 \quad .01$

$.14 \quad .01$

$.25 \quad .01$

$.01 \quad .002$

$.09 \quad .01$

$.11 \quad .01$

$.04 \quad .01$

$.12-.01$

$\begin{array}{ll}176.9 & 17.3\end{array}$

$.27 \quad .01$

$.15 \quad .01$

$\begin{array}{ll}13.8 & .84\end{array}$

16.8
12.8

$\begin{array}{ll}12.7 & .60\end{array}$

$\begin{array}{ll}.02 & .004\end{array}$

$\begin{array}{ll}.05 & .01\end{array}$

$.08 \quad .01$

$.18 \quad .01$

$\begin{array}{ll}.07 & .01 \\ .37 & .01\end{array}$

$.37 \quad .01$

$.01 \quad .003$

$\begin{array}{ll}.09 & .01\end{array}$

$.12 \quad .01$

$\begin{array}{ll}.41 & .01 \\ .36 & .01 \\ .69 & .01 \\ .29 & .01\end{array}$

There are 1039 observations in columns (1) and (2), and 1481 observations in columns (3) and (4). Standard errors of means are reported in parentheses. There are fewer observations for age, education, percentage of customers in each race group, and the demographic characteristics of the supervisor and respondent, because of missing data. In the following tables, a dummy variable for missing data on these variables is included, and the variables are set to zero. 
Table 2: Logit and Multinomial Logit Estimates of Effect of Affirmative Action on Demographic Group of Hire

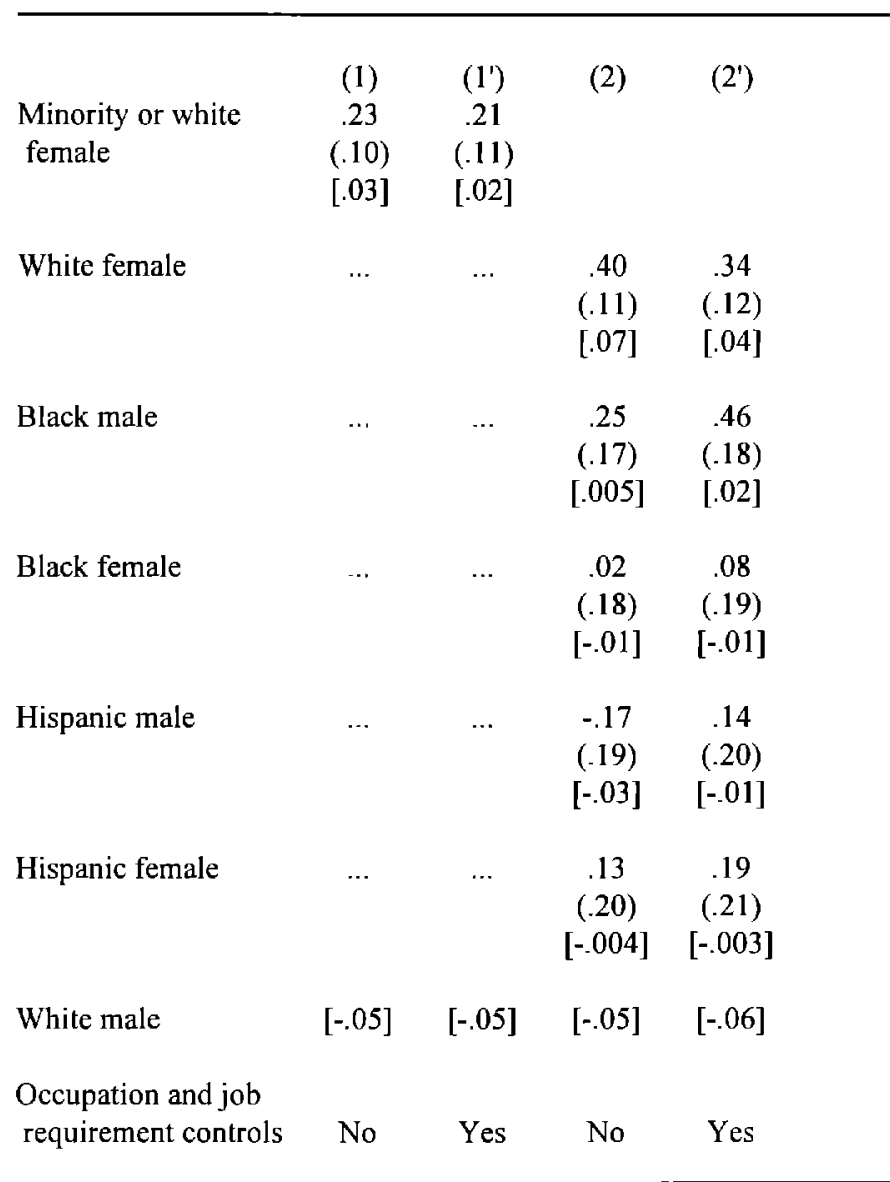

Estimated logit coefficients of dummy variable for Affirmative Action hire are reported in columns (1) and (1'), and multinomial coefficients in columns (2) and (2'). Estimates are reported relative to the omitted (white male) category. There are 2520 observations. All specifications include dummy variables for city and year and firm controls. Asian male and female hires are also included as outcomes, but results are not reported. In columns (1) and (2), "minority" refers to blacks and Hispanics. Standard errors of coefficient estimates are reported in parentheses. Marginal effects on probability of outcome evaluated at weighted sample means are reported in square brackets. Estimates are weighted. 
Equation:

$$
\mathrm{Q}_{\mathrm{ijk}}=\boldsymbol{\alpha} \mathrm{WM}_{\mathrm{ijk}} \cdot\left(1-\mathrm{AA}_{\mathrm{jk}}\right)+\beta \mathrm{D}_{\mathrm{ijk}} \cdot \mathrm{AA}_{\mathrm{jk}}+\gamma \mathrm{WM}_{\mathrm{ijk}} \cdot \mathrm{AA}_{\mathrm{jk}}+\delta \mathrm{D}_{\mathrm{ijk}} \cdot\left(1-\mathrm{AA}_{\mathrm{jk}}\right)+\theta \mathrm{X}_{\mathrm{j}}+\lambda \mathrm{Z}_{\mathrm{k}}{ }^{\prime}+\epsilon_{\mathrm{ijk}}
$$

Simple Differences:

$\beta-\gamma=$ woman/minority AA hire vs. white male AA hire

$\beta-\delta=$ woman/minority AA hire vs, woman/minority non-AA hire

$\beta-\alpha=$ woman $/$ minority AA hire vs. white male non-AA hire

Difference-in-differences:

$(\beta-\gamma)-(\delta-\alpha)=(\beta-\delta)-(\gamma-\alpha)=$

(woman/minority AA hire vs. white male AA hire) - (woman/minority non-AA hire vs. white male non-AA hire)

$$
=
$$

(woman/minority AA hire vs. woman/minority non-AA hire) - (white male AA hire vs. white male non-AA hire) 


\begin{tabular}{|c|c|c|c|c|}
\hline \multicolumn{5}{|c|}{ A. Firm Controls Only } \\
\hline AA hire: & $\begin{array}{c}\text { White male } \\
\text { AA hire } \\
\text { (1) }\end{array}$ & $\begin{array}{l}\text { Same demo. } \\
\text { group } \\
\text { non-AA hire } \\
\text { (2) }\end{array}$ & $\begin{array}{c}\text { White male } \\
\text { non-AA hire } \\
\text { (3) }\end{array}$ & $\begin{array}{c}\text { Difference-in- } \\
\text { differences } \\
\text { (4) }\end{array}$ \\
\hline White female & $\begin{array}{l}-.45 \\
(.16)\end{array}$ & $\begin{array}{c}.46 \\
(.13)\end{array}$ & $\begin{array}{l}.21 \\
(.14)\end{array}$ & $\begin{array}{l}-.20 \\
(.20)\end{array}$ \\
\hline Black male & $\begin{array}{r}-1.42 \\
(.23)\end{array}$ & $\begin{array}{l}.32 \\
(.27)\end{array}$ & $\begin{array}{l}-.77 \\
(.22)\end{array}$ & $\begin{array}{l}-.33 \\
(.31)\end{array}$ \\
\hline Black female & $\begin{array}{r}-1.64 \\
(.24)\end{array}$ & $\begin{array}{l}.28 \\
(.27)\end{array}$ & $\begin{array}{l}-.98 \\
(.23)\end{array}$ & $\begin{array}{l}-.38 \\
(.31)\end{array}$ \\
\hline Hispanic male & $\begin{array}{r}-2.49 \\
(.26)\end{array}$ & $\begin{array}{l}-.98 \\
(.28)\end{array}$ & $\begin{array}{r}-1.83 \\
(.25)\end{array}$ & $\begin{array}{r}-1.64 \\
(.32)\end{array}$ \\
\hline Hispanic female & $\begin{array}{c}-2.42 \\
(.28)\end{array}$ & $\begin{array}{l}-.16 \\
(.32)\end{array}$ & $\begin{array}{r}-1.76 \\
(.27)\end{array}$ & $\begin{array}{l}-.81 \\
(.36)\end{array}$ \\
\hline \multicolumn{5}{|c|}{ B. Occupation and Job Requirement Controls Added } \\
\hline White female & $\begin{array}{l}-.64 \\
(.14)\end{array}$ & $\begin{array}{l}.22 \\
(.11)\end{array}$ & $\begin{array}{l}-.28 \\
(.12)\end{array}$ & $\begin{array}{l}-.14 \\
(.17)\end{array}$ \\
\hline Black male & $\begin{array}{l}-.76 \\
(.20)\end{array}$ & $\begin{array}{c}.24 \\
(.23)\end{array}$ & $\begin{array}{l}-.39 \\
(.19)\end{array}$ & $\begin{array}{l}-.13 \\
(.27)\end{array}$ \\
\hline Black female & $\begin{array}{r}-1.28 \\
(.21)\end{array}$ & $\begin{array}{c}.19 \\
(.23)\end{array}$ & $\begin{array}{l}-.92 \\
(.20)\end{array}$ & $\begin{array}{l}-.17 \\
(.27)\end{array}$ \\
\hline Hispanic male & $\begin{array}{r}-1.51 \\
(.23)\end{array}$ & $\begin{array}{l}-.56 \\
(.24)\end{array}$ & $\begin{array}{r}-1.15 \\
(.22)\end{array}$ & $\begin{array}{l}-.92 \\
(.27)\end{array}$ \\
\hline Hispanic female & $\begin{array}{r}-1.98 \\
(.24)\end{array}$ & $\begin{array}{l}-.44 \\
(.27)\end{array}$ & $\begin{array}{r}-1.61 \\
(.23)\end{array}$ & $\begin{array}{l}-.80 \\
(.30)\end{array}$ \\
\hline \multicolumn{5}{|c|}{$\begin{array}{l}\text { There are } 2388 \text { observations. Standard errors are reported in parentheses. All specifications include dummy } \\
\text { variables for city and year and firm controls, as well as dummy variables and interactions for Asian males } \\
\text { and females. In Panel B educational requirements are not included. There are fewer observations than in the } \\
\text { previous tables because of missing data on the recent hire's actual schooling. The educational variable is } \\
\text { coded as follows: drop out ( } 10 \text { years); GED ( } 11 \text { years); high school graduate ( } 12 \text { years); trade school or some } \\
\text { college ( } 13 \text { years); AA degree ( } 14 \text { years); Bachelor's degree ( } 16 \text { years); some graduate school ( } 17 \text { years); and } \\
\text { graduate degree ( } 18 \text { years). Estimates are weighted. The difference-in-differences estimates in column (4) } \\
\text { correspond to either of the following two equivalent relative comparisons: (woman/minority AA hire vs. } \\
\text { white male AA hire) - (woman/minority non-AA hire vs. white male non-AA hire); or (woman/minority } \\
\text { AA hire vs. woman/minority non-AA hire) - (white male AA hire vs. white male non-AA hire). A relevant } \\
\text { differences-in-differences estimate with respect to the estimates in column (3) is (woman/minority AA hire } \\
\text { vs. white male non-AA hire) - (woman/minority non-AA hire vs. white male non-AA hire). This estimate } \\
\text { corresponds to those in column (2). }\end{array}$} \\
\hline
\end{tabular}


AA hire:

White female

Black male

Hispanic male

Hispanic female

Black male

Black female

$(.50)$
$[.07]$

Hispanic male

Hispanic female

.73

\section{A. Firm Controls Only}

Difference relative to:

\section{White male \\ AA hire}

(1)

\section{Same demo. \\ group}

(2)
non-AA hire non-AA hire

(3)
White male
Difference-indifferences

(4)

$\begin{array}{lccc}.39 & -.01 & .67 & -.30 \\ (.39) & (.31) & (.36) & (.52) \\ {[.02]} & {[-.001]} & {[.04]} & {[-.02}\end{array}$

$-.30$

[-.02]

1.10

1.01

.81

(.75)

(.49)

(.86)

[.04]

[.06]

[.06]

[.05]

1.41

1.74

1.69

1.46

(.70)

(.48)

(.82)

[.08]

[.10]

[.10]

.003

(.79)

[.000]

(.59)

[.03]

.84

(.87)

[.05]

\section{B. Occupation and Job Requirement Controls Added}

$\begin{array}{ll}.18 & -.04 \\ (.41) & (.32) \\ {[.01]} & {[-.002]}\end{array}$

.79

1.29

.63

(.63)

[.04]

.84

(.57)

$[.05]$
$(.32)$

\section{.98}

(.76)

[.06]

1.60

$(.70)$

[.09]

$\begin{array}{lc}1.02 & .03 \\ (.61) & (.83) \\ {[.06]} & {[.002]} \\ 1.23 & .55 \\ (.57) & (.88) \\ {[.07]} & {[.03]}\end{array}$

There are 2073 observations in Panel A, and 2063 in Panel B. Standard errors are reported in parentheses, and partial derivatives evaluated at weighted sample means in square brackets. All specifications include dummy variables for city and year and firm controls, as well as dummy variables and interactions for Asian males and females. The dependent variable is coded as one if the job requires a college degree and the hire has less than a college degree, or the job requires a high school degree and the hire has less than a high school degree (including a GED). We assume that a required college degree refers to a Bachelor's degree. In Panel B the educational requirements are not included. The sample is smaller than in the previous table because data on the education requirement for the job is needed. The number of observations varies with the number of independent variables (or combinations thereof) which serve as perfect predictors of the dependent variable. Estimates are weighted. See footnotes to Table 3 for additional details. 


\begin{tabular}{|c|c|c|c|c|}
\hline \multirow[b]{3}{*}{ A A : } & \multicolumn{3}{|c|}{ A. Firm Controls Only } & \multirow[b]{3}{*}{$\begin{array}{c}\text { Difference-in- } \\
\text { differences } \\
\text { (4) }\end{array}$} \\
\hline & \multicolumn{3}{|c|}{ Difference relative to: } & \\
\hline & $\begin{array}{l}\text { White male } \\
\text { AA hire } \\
\text { (1) }\end{array}$ & $\begin{array}{l}\text { Same demo. } \\
\text { group } \\
\text { non-AA hire } \\
\text { (2) }\end{array}$ & $\begin{array}{c}\text { White male } \\
\text { non-AA hire } \\
\text { (3) }\end{array}$ & \\
\hline \multirow[t]{2}{*}{ White female } & .15 & .36 & .52 & -.003 \\
\hline & $(.12)$ & $(.10)$ & $(.11)$ & $(.16)$ \\
\hline \multirow[t]{2}{*}{ Black male } & -1.04 & .17 & -.67 & -.20 \\
\hline & $(.19)$ & $(.21)$ & $(.18)$ & $(.25)$ \\
\hline \multirow[t]{2}{*}{ Black female } & -.27 & .52 & .10 & .15 \\
\hline & $(.19)$ & $(.22)$ & $(.19)$ & $(.25)$ \\
\hline \multirow[t]{2}{*}{ Hispanic male } & -1.34 & -.14 & -.97 & -.51 \\
\hline & $(.21)$ & $(.22)$ & $(.20)$ & $(.25)$ \\
\hline \multirow[t]{2}{*}{ Hispanic female } & -.09 & 1.16 & .28 & .79 \\
\hline & $(.22)$ & $(.26)$ & $(.22)$ & $(.28)$ \\
\hline \multicolumn{5}{|c|}{ B. Occupation Controls Added } \\
\hline \multirow[t]{2}{*}{ White female } & -.09 & .28 & .20 & -.01 \\
\hline & $(.12)$ & $(.10)$ & $(.11)$ & $(.15)$ \\
\hline \multirow[t]{2}{*}{ Black male } & -.76 & .08 & -.47 & -.21 \\
\hline & $(.18)$ & $(.20)$ & $(.17)$ & $(.23)$ \\
\hline \multirow[t]{2}{*}{ Black female } & -.26 & .46 & .03 & .18 \\
\hline & (.18) & $(.20)$ & $(.18)$ & $(.23)$ \\
\hline \multirow[t]{2}{*}{ Hispanic male } & -.87 & .02 & -.58 & -.27 \\
\hline & $(.20)$ & (.21) & $(.19)$ & $(.24)$ \\
\hline \multirow[t]{2}{*}{ Hispanic female } & .05 & 1.11 & .34 & .82 \\
\hline & $(.21)$ & $(.24)$ & $(.20)$ & $(.27)$ \\
\hline
\end{tabular}

There are 2520 observations. Standard errors are reported in parentheses, and partial derivatives evaluated at weighted sample means in square brackets. City and year dummy variables and firm controls, as well as dummy variables and interactions for Asian males and females. Estimates are weighted. See footnotes to Table 3 for additional details. 


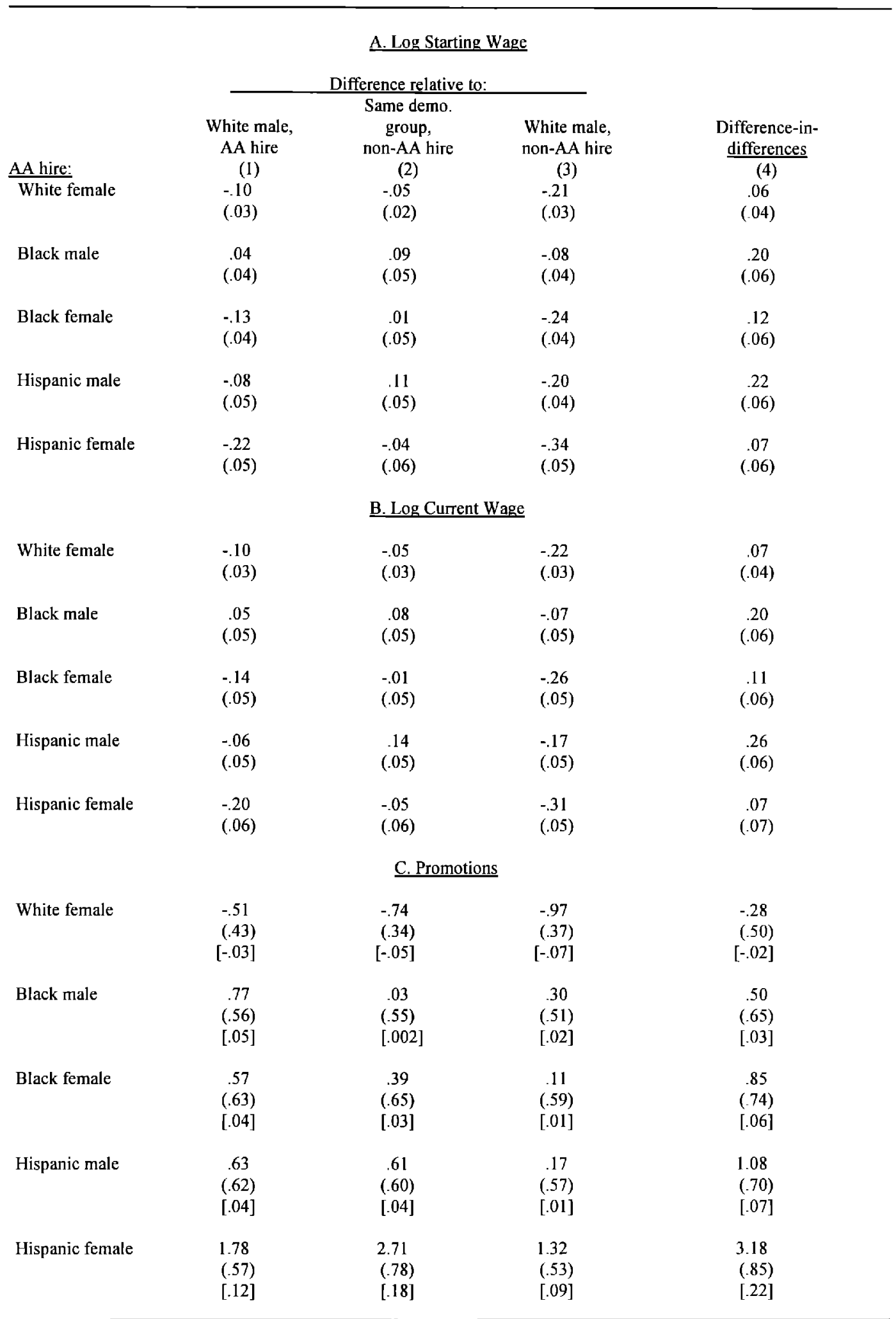

There are 2141 observations in Panels A and B, and 2445 in Panel C. Standard errors are reported in parentheses, and partial derivatives evaluated at weighted sample means in square brackets. All specifications include dummy variables for city and year and firm, occupation, and job requirement controls. In addition, controls for education, age, tenure (in all but the starting wage regression), and dummy variables for different race or sex of respondent or supervisor are included. Estimates are weighted. See footnotes to Table 3 for additional details. 


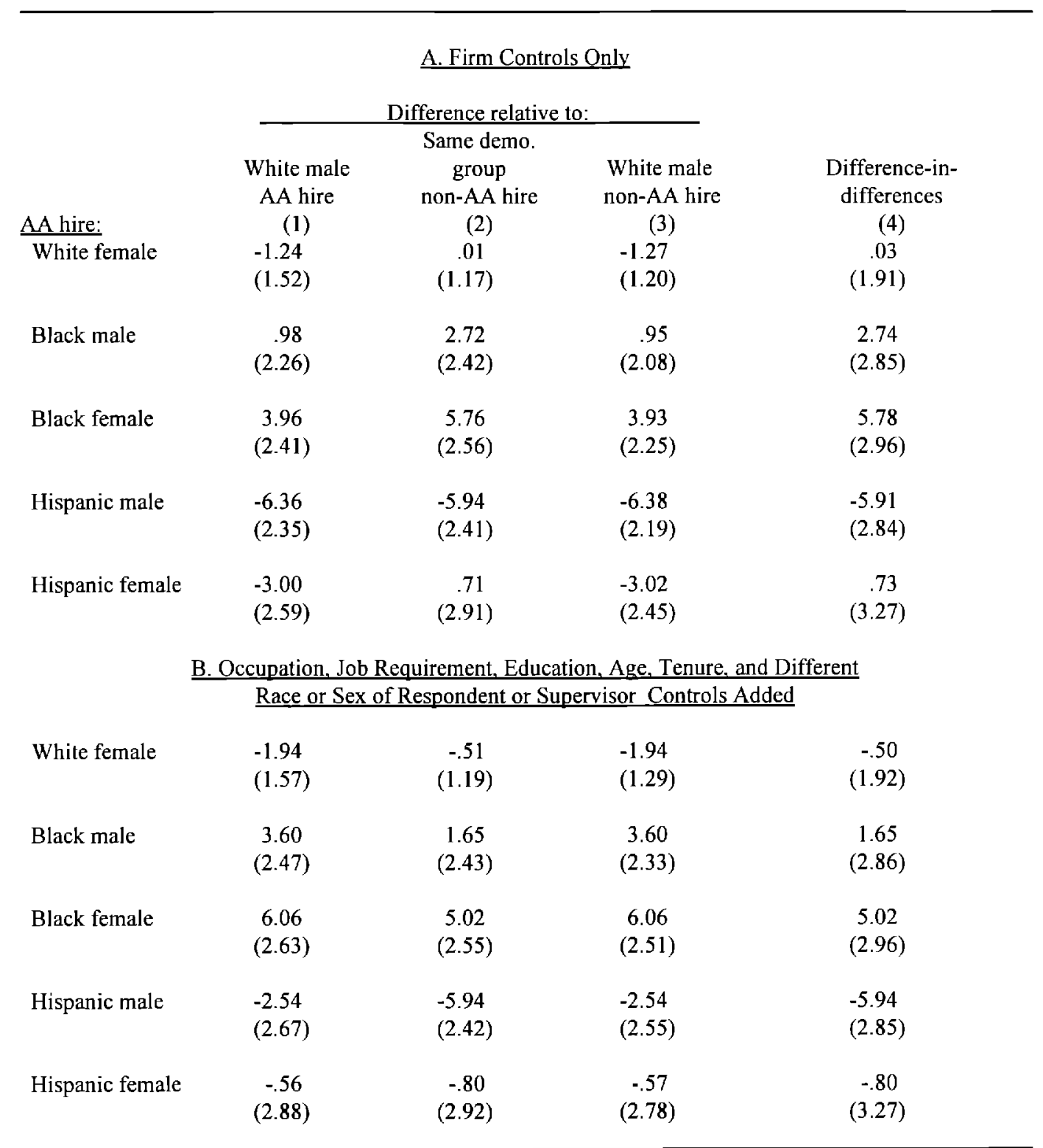

There are 2134 observations. Standard errors are reported in parentheses. All specifications include dummy variables for city and year and firm, occupation, and job requirement controls. Estimates are weighted. See footnotes to Table 3 for additional details. 


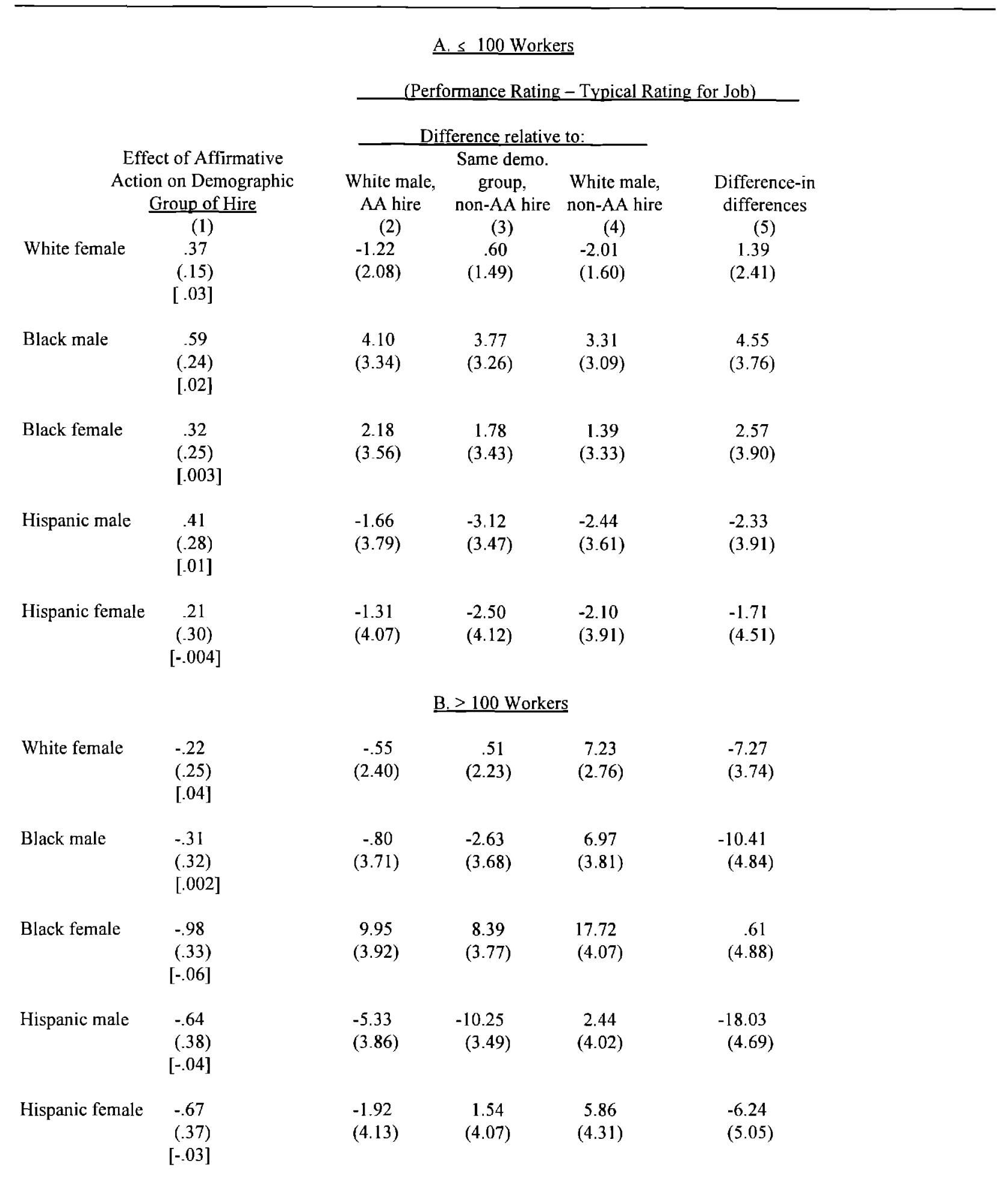

Estimates in column (1) correspond to those in column (2') of Table 2. Estimates in columns (2)-(5) correspond to those in Panel $\mathrm{B}$ of Table 7. In Panel A, there are 1643 observations in column (1), and 1476 in columns (2)-(5). The corresponding sample sizes for Panel $\mathrm{B}$ are 876 and 658 . See footnotes to Tables 2, 3 and 7 for more details. 